\title{
Contraception continuation rates and reasons for discontinuation in Zahedan, Islamic Republic of Iran
}

F. Rakhshani' and M. Mohammadi²

$$
\begin{aligned}
& \text { معدلات الاستمرار في تعاطي مانعات الحمل وأسباب توقيفها في زاهدان بجمهورية إيران الإسلامية } \\
& \text { فاطمة رَخشاني، مهاندي محمدي }
\end{aligned}
$$

ABSTRACT We evaluated contraception continuation rates and discontinuation reasons in Zahedan among 1741 women from 1998-2000. By Kaplan-Meier technique continuation rates were $92 \%$ for low dose combined hormonal oral contraceptives (OC), 86\% for a levonorgestrel-releasing implant, $82 \%$ for intrauterine devices (IUD) and $53 \%$ for medroxyprogesterone acetate at the first year. After 3 years, continuation was $78 \%$ for levonorgestrel implant, $70 \%$ for OC, $60 \%$ for IUD and $44 \%$ for medroxyprogesterone acetate. The commonest reason for discontinuing $\mathrm{OC}$ and medroxyprogesterone acetate was changing method; for IUD and levonorgestrel-releasing implant, the commonest reason was side-effects. By Cox regression model, continuation rate and contraceptive type were significantly related to health centre.

Taux de poursuite de la contraception et raisons d'abandon à Zahedan (République islamique d'Iran)

RESUME Nous avons évalué les taux de poursuite de la contraception et les raisons d'abandon à Zahedan chez 1741 femmes durant la période de 1998 à 2000. Le taux de poursuite, calculé selon la technique de Kaplan-Meier, s'élevait à $92 \%$ pour la pilule contraceptive orale combinée à faible dosage hormonal, à $86 \%$ pour les implants libérant du lévonorgestrel, à $82 \%$ pour les dispositifs intra-utérins (DIU) et à $53 \%$ pour l'acétate de médroxyprogestérone durant la première année. Après trois ans, la poursuite de la contraception était de $78 \%$ pour les implants au lévonorgestrel, $70 \%$ pour les contraceptifs oraux, $60 \%$ pour les DIU et $44 \%$ pour l'acétate de médroxyprogestérone. La raison la plus courante pour l'abandon des contraceptifs oraux et de l'acétate de médroxyprogestérone était le changement de méthode ; pour les DIU et les implants au lévonorgestrel, les effets secondaires constituaient le motif le plus courant. En utilisant le modèle de régression de Cox, le taux de poursuite et le type de contraceptif étaient significativement liés et ils différaient selon le centre de santé.

${ }^{1}$ Department of Public Health; ${ }^{2}$ Department of Epidemiology and Biostatistics, Faculty of Health, Zahedan Medical Sciences University, Zahedan, Islamic Republic of Iran.

Received: 08/12/02; accepted: 13/05/03

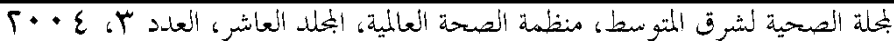




\section{Introduction}

The quality of family planning services is an important determinant of contraceptive use because it is likely to affect contraceptive continuation [1]. By controlling reproduction, women will be able to reach other goals besides having children [2]. All personnel involved in family planning projects are aware that to attract new users, they must keep previous users. The rate at which users discontinue a method of contraception is one of the major indicators of quality of use [3]. High discontinuation rates can increase the number of unwanted and high-risk pregnancies. In 15 Asian countries more than half of unwanted fertility was due to either a contraceptive failure or discontinuation of a method [1].

Many studies have investigated the continuation of contraceptive methods. A study in Egypt revealed that the continuation rate of contraceptive methods was $88 \%$ for the first 6 -months, $75 \%$ for 12 -months and $56 \%$ for 24 -months. Three predictive factors were important for discontinuation: side-effects, female age and method type. In Benin and Eastern Africa, the continuation rate of contraceptive injections was $51.9 \%$ for the first year [3]. In a study in the United Kingdom, the continuation rates for a levonorgestrel-releasing implant system (Norplant, Wyeth Laboratories, Taplow, United Kingdom) and IUD were $72 \%$ and $55 \%$ respectively after 24 months [4].

A comparative multicentre clinical trial of oral contraceptives was conducted in Malaysia, Egypt, Thailand and Mexico and revealed that the 11-month discontinuation rate was $28.8 \%$ [3]. Discontinuation rates due to menstrual problems, side-effects and other medical reasons were $7.1 \%$, $5.1 \%$ and $3.8 \%$ respectively [3]. In the United States of America, 36\% of injection consumers discontinued the method because of side-effects and menstrual disorders and 39\% because of weight increase, headache, mood change and acne [3].

The main goal of family planning projects is to improve the quality of contraceptive methods; therefore, the rate of discontinuation of contraceptive methods is one of the main indicators of quality of usage. Because high rates of discontinuation are major problems for family planning programmes, an evaluation of their effective factors is necessary [2].

Zahedan is in the province of Sistan and Baluchistan in the south-eastern part of the Islamic Republic of Iran. The province borders Pakistan and Afghanistan on the east and the Oman Sea on the south. There are 7 towns in the province and Zahedan is central. Zahedan has a population of approximately 500000 people. About $60 \%$ of the people use contraceptive methods. Family planning indices in this province are lower than for the country as a whole. In our country, the national health system is based on the primary health care (PHC) approach and one of the reproductive health strategies is to enhance the quality of services in family planning programmes.

There is not enough information about continuation rates of contraceptive methods in Zahedan, so our aim was to study contraception use, continuation and discontinuation and their causes. Understanding the causes of discontinuation can facilitate consultations with clients and improve the quality of service.

\section{Methods}

This was a historical cohort study, which used documents in the health centres in Zahedan in 2001. All women in our study were Iranian and had started a contracep-

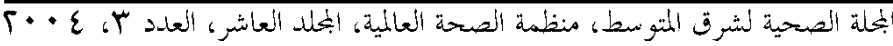


tive method, including low dose combined hormonal oral contraceptive pills, intrauterine devices (IUD), medroxyprogesterone acetate or levonorgestrel implant between early 1998 and late 2000. We divided the city into 5 areas and randomly chose 1 health centre from each area. All necessary information was gathered from these 5 centres. Files without the required information were excluded from the study $(6 \%)$. A total of 1741 samples were studied. Of these, $388(22.3 \%)$ who used mini pills (lynestronol) were excluded from the analysis. Therefore, 1353 women were included: 853 women who started with low dose combined contraception, 224 with medroxyprogesterone acetate, 222 with IUD and 54 with levonorgestrel implant. Chi-squared, one-way analysis of variation, log-rank, Cox regression model and Kaplan-Meier were used for data analysis.

\section{Results}

The mean ages of women and their husbands were $27 \pm 5.7$ years and $33 \pm 8.2$ years respectively. Of the women, $53.6 \%$ were illiterate or with elementary education and $89.6 \%$ were housewives. The mean number of children was $2.8 \pm 1.9$. The mean age of the last child was $2.8 \pm 1.7$ years. Overall $71.2 \%$ of women used different kinds of oral contraceptive pills, $12.9 \%$ used medroxyprogesterone acetate, $12.7 \%$ used IUD and $3.1 \%$ used levonorgestrel implant. One-way ANOVA showed a significant relation between women's age and number of children to method type ( $P$ $<0.05)$. The mean age and the mean number of children were lower for women who used low dose combination hormonal oral contraceptive pills and IUD than for those who used medroxyprogesterone acetate and levonorgestrel-releasing implant systems. Chi-squared analysis did not show any significant relationship between job and method type, but there was significant relation between education and method type ( $P$ $<0.001)$. Women with higher education were more likely to use IUD and levonorgestrel-releasing implant systems whereas women with less education were more likely to use medroxyprogesterone acetate.

Table 1 shows the continuation rates of contraceptive methods during the 3 years from 1998-2000 in Zahedan. In the first 12

Table 1 Continuation rates of contraceptive methods used in Zahedan from early 1998 until late 2000

\begin{tabular}{|c|c|c|c|c|}
\hline $\begin{array}{l}\text { Levonorgestrel- } \\
\text { releasing implant } \\
\text { (\%) }\end{array}$ & $\begin{array}{l}\text { IUD } \\
(\%)\end{array}$ & $\begin{array}{c}\text { Medroxyprogesterone } \\
\text { acetate }(\%)\end{array}$ & $\begin{array}{c}\text { Low dose combined } \\
\text { OC pills (\%) }\end{array}$ & $\begin{array}{c}\text { Duration of } \\
\text { use (months) }\end{array}$ \\
\hline 86 & 82 & 70 & 92 & 6 \\
\hline 78 & 76 & 54 & 83 & 12 \\
\hline 78 & 74 & 47 & 78 & 18 \\
\hline 78 & 68 & 44 & 73 & 24 \\
\hline 78 & 68 & 44 & 72 & 30 \\
\hline 78 & 60 & 44 & 70 & 36 \\
\hline
\end{tabular}

IUD = intrauterine device.

$O C=$ oral contraceptive.

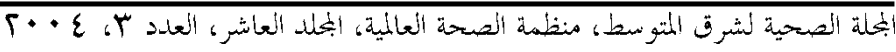


months, medroxyprogesterone acetate was least likely to be continued and low dose combined hormonal oral contraceptive pills were most likely to be continued. At 18 months low dose combined hormonal oral contraceptive pills and levonorgestrel implants were the most likely to be continued. From 24 to 36 months, levonorgestrel implants had the highest continuation rate, followed by low dose combined hormonal oral contraceptive pills, IUD and medroxyprogesterone acetate respectively. The continuation rate for levonorgestrel implants levelled off at $78 \%$ after 12 months.

The continuation rates of the 4 contraceptive methods were not significantly related to age, age of husband, education, education of husband, number of children or age of last child by log-rank test. However, log-rank test showed a significant difference in continuation rates of different contraceptives $(P<0.001)$ (Figure 1$)$. Continuation rates among the 5 health centres were also significantly different $(P<$ 0.001) (Table 2). Levonorgesterol was not entered into the analysis because the sample size was not adequate. A Cox proportional hazards model was used to evaluate the possible effects of contraceptive methods on the continuation rate adjusted for the centre effect. In this way, we could calculate the odds ratios for contraceptives adjusted for centre in the model.

Based on the Cox regression model, the chance of discontinuing medroxyprogesterone acetate was 3.3 times that of oral contraceptive pills $(P<0.001)$; discontinuing IUD was 6 times that of oral contraceptive pills $(P=0.006)$; and discontinuing the levonorgestrel implant was 1.3 times that of oral contraceptive pills $(P=0.55)$. Among all studied women, 31\% discontin-

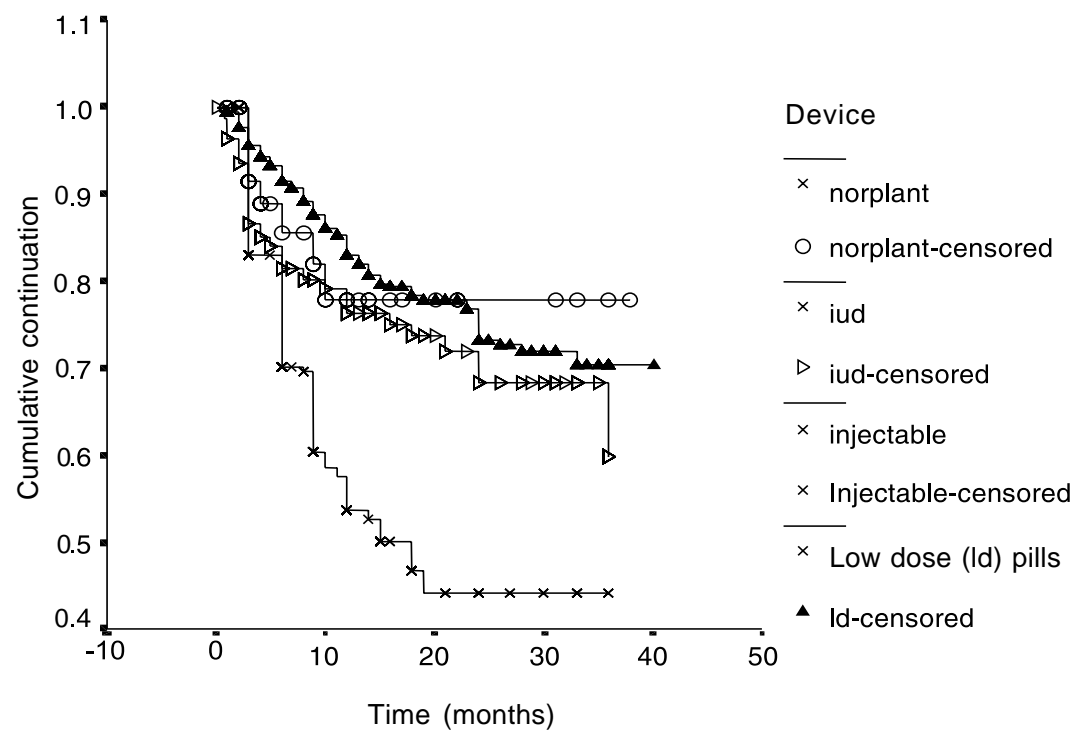

Figure 1 Comparison of continuation rates of 4 contraceptive methods over 3 years (log rank $=70.98, d f=3, P<0.0001$ )

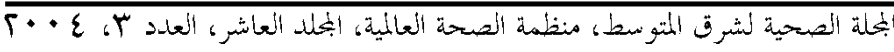


Table 2 Continuation rates of contraceptives by health centre from 1998-2000

\begin{tabular}{|c|c|c|c|c|c|c|c|c|c|}
\hline \multirow[t]{2}{*}{ Centre } & \multicolumn{3}{|c|}{ Low dose combined OC } & \multicolumn{3}{|c|}{ Medroxyprogesterone acetate } & \multicolumn{3}{|c|}{ Intrauterine device } \\
\hline & $\begin{array}{c}6 m \\
\%\end{array}$ & $\begin{array}{c}12 m \\
\%\end{array}$ & $\begin{array}{c}18 m \\
\%\end{array}$ & $\begin{array}{c}6 m \\
\%\end{array}$ & $\begin{array}{c}12 m \\
\%\end{array}$ & $\begin{array}{c}18 m \\
\%\end{array}$ & $\begin{array}{c}6 m \\
\%\end{array}$ & $\begin{array}{c}12 m \\
\%\end{array}$ & $\begin{array}{c}18 m \\
\%\end{array}$ \\
\hline 1 & 83 & 72 & 71 & 57 & 29 & 22 & 82 & 74 & 74 \\
\hline 2 & 98 & 83 & 75 & 79 & 73 & 64 & 92 & - & - \\
\hline 3 & 99 & 95 & 90 & 92 & 81 & 74 & 82 & 75 & 71 \\
\hline 4 & 96 & 86 & 79 & 65 & 36 & - & 78 & 76 & 76 \\
\hline \multirow[t]{2}{*}{5} & 85 & 74 & 68 & 48 & 29 & 19 & 75 & 75 & 63 \\
\hline & \multicolumn{3}{|c|}{$\mathrm{LR}=35.14, \mathrm{df}=4, P<0.001$} & \multicolumn{3}{|c|}{$\mathrm{LR}=45.3, \mathrm{df}=4, P<0.001$} & \multicolumn{3}{|c|}{ (Too few events to analyse } \\
\hline
\end{tabular}

OC $=$ oral contraceptive pills

$m=$ months.

$\mathrm{LR}=\log$ rank; $\mathrm{df}=$ degrees of freedom.

ued the methods for different reasons and $56.3 \%$ continued. There was no information available about the outcome of the other $12.7 \%$. Overall $21.7 \%$ of the women changed their methods $1-3$ times during those 3 years.

Table 3 shows reasons for discontinuation. The commonest reason for low dose combined hormonal oral contraceptive pills $(84.9 \%)$ and for medroxyprogesterone ac- etate $(84.9 \%)$ was to change contraceptive method and the commonest reason for IUD (68\%) and for levonorgestrel implant $(62.5 \%)$ discontinuation was side-effects.

\section{Discussion}

The most commonly used method in the Zahedan was oral contraceptive pills,

\begin{tabular}{|c|c|c|c|c|c|c|c|c|}
\hline \multirow[t]{2}{*}{$\begin{array}{l}\text { Reason for } \\
\text { discontinuation }\end{array}$} & \multicolumn{2}{|c|}{$\begin{array}{c}\text { Low dose combined } \\
\text { OC }\end{array}$} & \multicolumn{2}{|c|}{ IUD } & \multicolumn{2}{|c|}{$\begin{array}{c}\text { Medroxyprogesterone } \\
\text { acetate }\end{array}$} & \multicolumn{2}{|c|}{$\begin{array}{l}\text { Levonorgestrel- } \\
\text { releasing implant }\end{array}$} \\
\hline & No. & $\%$ & No. & $\%$ & No. & $\%$ & No. & $\%$ \\
\hline Change of method & 337 & 84.9 & 8 & 16 & 73 & 84.9 & 3 & 37.5 \\
\hline $\begin{array}{l}\text { Pregnancy while } \\
\text { using }\end{array}$ & 41 & 10.4 & 3 & 6 & 3 & 3.5 & - & - \\
\hline $\begin{array}{l}\text { Desire to have a } \\
\text { child }\end{array}$ & 10 & 2.5 & 3 & 8 & - & - & - & - \\
\hline Side-effects & 6 & 1.5 & 34 & 68 & 8 & 9.4 & 5 & 62.5 \\
\hline Other reasons & 1 & 0.7 & 1 & 2 & 3 & 2.2 & - & - \\
\hline Total & 395 & 100 & 49 & 100 & 87 & 100 & 8 & 100 \\
\hline
\end{tabular}

$O C=$ oral contraceptive pills.

IUD = intrauterine device. 
which is similar to the United States of America and 15 Asian countries, whereas the commonest method in Egypt was IUD $[1,3,5]$. In Zahedan medroxyprogesterone acetate and IUD are the most commonly used methods after oral contraceptive pills. In our study women with more years of education were more likely to use levonorgestrel implant and IUD and women with fewer years of education were more likely to use medroxyprogesterone acetate. In Egypt, methods were not significantly related to education [3]. A larger proportion of women in our Zahedan study were educated than in the Egyptian study; therefore, the difference might have been due to education in Egypt that affected the behaviours of uneducated and educated women similarly.

There was no significant relation between method and type of job in our study, which is similar to results from the Egyptian study [3]. Women who used levonorgestrel implant and medroxyprogesterone acetate were older than users of other methods in this study and in Egypt [3]. This was probably due to the relationship of number of children to method used; women with more children may look for more effective methods even though they are not interested in using permanent methods.

The continuation rate of low dose combined hormonal oral contraceptive pills was $92 \%$ in Zahedan and $72 \%$ in the USA in the first 6 months [5]. It rose to $83 \%$ in $\mathrm{Za}$ hedan after 1 year and was 52\% in Egypt and $40.8 \%$ at Benin after 1 year $[3,6]$. The continuation rates of low dose combined hormonal oral contraceptive pills were $73 \%$ and $70 \%$ after 2 and 3 years in Zahedan, which were higher than in similar studies. A study in Tehran found that the highest percentage of duration of use was $>4$ years $(33 \%)$ [7].
Medroxyprogesterone acetate continuation rates are $54 \%$ at 12 months, $44 \%$ at 24 months and $44 \%$ at 36 months. In Egypt, they were $43 \%$ at 1 year and $40 \%$ at 2 years. In Benin, they were $51.9 \%$ in the first year and in a cohort study $42 \%$ at 1 year and $21 \%$ at 2 years $[3,8]$. These results indicate low continuation rates of injection among women in various countries. These rates may be due to side-effects that prompt women to change the method. Women with less education were initially more interested in this method because they were not aware of its side-effects and when they encountered the first sideeffect, they discontinued use.

IUD continuation rates were $76 \%$ at 12 months, $68 \%$ in at months and $60 \%$ at 36 months in Zahedan. In Isfahan they were $79 \%$ at 1 year and $59 \%$ at 2 years [9]. IUD continuation rates were $72 \%$ at 1 year and $63 \%$ at 2 years in Egypt [3]. In Scotland the IUD discontinuation rate was $55 \%$ at 1 year, in India it was $65 \%$ at 4 months, and in Papua New Guinea it was $92 \%$ at 1 year $[4,7,10]$. The IUD continuation rate in Zahedan therefore was higher than in other places. Most IUD users in Zahedan had higher education and probably chose the method with more initial knowledge; therefore, they were less likely to change the method.

Levonorgestrel implant continuation rates were $78 \%$ at 1 year, $78 \%$ at 2 years and $78 \%$ at 3 years. Levonorgestrel implant continuation rates were $79 \%$ at 1 year and $69 \%$ at 2 years in Egypt. In Singapore, they were $90 \%, 78 \%, 70 \%, 61 \%$ and $42 \%$ for the first year and each year up to 5 years [4]. In Scotland, it was $72 \%$ for 24 months [4]. The results of our study, therefore, are similar to other studies perhaps because the women in our study who used this method were more educated. Continuation rates

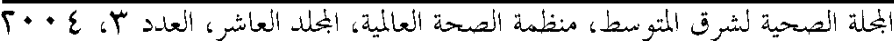


were constant from month 12 onwards; we conclude that those who use the levonorgestrel implant for 1 year are likely continue it from then on. In our study only 54 women used the levonorgestrel implant and perhaps the small number of users affected the results. With a larger sample, we might observe different results.

Log-rank test showed that the continuation rates of the 4 studied methods were not related to the woman's education, husband's education, number of children, or age of the last child. In the USA, variables such as specific side-effects, age, quality of patient-provider interaction and psychological variables were not predictive of oral contraceptive discontinuation [5].

In Zahedan, $31 \%$ of women discontinued methods during the 3 years of our study and the commonest reason was changing method. During the 3 years, $21.7 \%$ of women changed their methods 1-3 times. Discontinuation is a common event in all countries as $9 \%-34 \%$ of women discontinue methods due to service quality [1]. In Egypt, side-effects and health concerns of the method were the commonest reasons for discontinuation [3]. Common user complaints and side-effects were the reasons for discontinuation that were related to the methods, but these types of reasons also included misperceptions regarding relative risks of methods and low tolerance for a method's disadvantages [6].

In Zahedan, the main reason for low dose combined hormonal oral contraceptive pills discontinuation was changing method, but in Tehran it was medical reasons [7]. In other studies the main reason of discontinuation was menstrual disorders [3]. Side-effects were the main reason for discontinuation in the USA [5]. Discontinu- ation of oral contraception and its later reuse indicates hurried selection of methods.

The commonest reason for IUD discontinuation in Zahedan was side-effects; this was similar to Egypt and 15 Asian countries, whereas in Isfahan the main reason for discontinuation was changing the method $[1,3,9]$.

The commonest reason in Zahedan for medroxyprogesterone acetate discontinuation was changing method. Only 9\% changed because of side-effects, whereas side-effects were the commonest reason for its discontinuation in Mashhad, Egypt and the USA $[3,11]$. In another cohort study menstrual disorders were the main reason for discontinuation [7]. Levonorgestrel implant discontinuation in Zahedan was due to side-effects, which is similar to studies in Isfahan, Egypt and India $[3,7,12]$. Since only 8 of 54 women discontinued levonorgestrel implant in $\mathrm{Za}$ hedan, we cannot draw a clear conclusion.

The continuation rates of contraceptive methods in the health centres in Zahedan were significantly different. With the Cox model we even observed a difference by type of method at each centre. Some reasons for these differences might be varying styles of communication in the initial interview with a new client, the quality of fieldworker care, and client and staff expectations and interactions in the centres $[10,13,14]$. It has been reported that proper consultations when a women is choosing the injection method of contraception is an effective strategy to decrease discontinuation [7]. We need more studies to understand effective factors so that we can make changes towards improving continuity of contraceptive methods.

Counselling should emphasize the possibility of side-effects and inform women

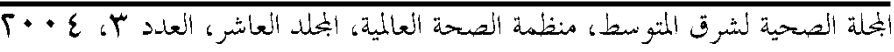


that most side-effects are transient. Consultations should also identify backup methods for women. Follow-up visits should be scheduled for 6 months after a prescription is written.

\section{Acknowledgements}

We thank the Research Board of the College of Medicine, Dr Malek Kiyani and the personnel of the Zahedan health centres.

\section{References}

1. Blanc AK, Curtis S, Croft T. Does contraceptive discontinuation matter? Quality of care and fertility consequences. MEASURE evaluation technical report series No. 3. Chapel Hill, North Carolina, USA, Carolina Population Center. University of North Carolina at Chapel Hill, 1999:105.

2. Berek JS et al. Novak's gynecology, 12th ed. Philadelphia, Lippincott, Williams and Wilkins, 1996:227-8.

3. Mahdy NH et al. Probability of contraceptive continuation and its determinants. Eastern Mediterranean health journal, 1999, 5(3):526-38.

4. Fleming $D$ et al. Continuation rates of long-acting methods of contraception. Family planning and well woman service, 1998, 57(1):19-21.

5. Rosenberg MJ, Waugh MS. Oral contraceptive discontinuation: A prospective evaluation of frequency and reasons. American journal of obstetrics and gynecology, 1998, 179(3):577-82.

6. Matteson PS, Hawkins JW. What family planning methods women use and why they change them. Health care for women international, 1993, 14(6):53948.

7. Noroumanesh $\mathrm{SH}$, Faghihzadeh $\mathrm{M}$, Lamieyan M. Study of application, causes of the discontinuation and problems of oral contraceptive pills. Journal of the Faculty of Medicine, Tehran University, 1996, 54(2-3):78-82.
8. Beksinska ME, Rees HV, Smit J. Temporary discontinuation: a compliance issue in injectable users. Contraception, 2001, 64(5):309-13.

9. Chitsaz F et al. The probabilities of continuation of IUD and its determinants in urban health centres in Isfahan. Paper presented at the Second National Congress of Public Health and Preventive Medicine, Kermanshah, Islamic Republic of Iran, 6-9 November 2001.

10. Townsend PK. Contraceptive continuation rates in Papua New Guinea. Papua New Guinea medical journal, 1983, 26(2):114-21.

11. Poorjavad M. One-year study about the reasons of discontinuance of injectable hormonal contraceptives in Mashhad. Medical journal of Mashhad University of Medical Sciences, 1998, 41(59-60): 107-11.

12. Mostajeran F, Shabanian M. Efficacy and side-effects of Norplant contraceptive implants in Isfahan. Journal of Isfahan Medical School, 1998, 16(50):87-93.

13. Koenig MA, Hossain MB, Whittaker M. The influence of quality of care upon contraceptive use in rural Bangladesh. Studies in family planning, 1997, 28(4): 278-89.

14. Nathanson CA, Becker $\mathrm{MH}$. The influence of client-provider relationships on teenage women's subsequent use of contraception. American journal of public health, 1985, 75(1):33-8.

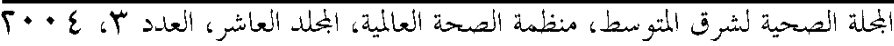

